\title{
Glycyrrhiza Glabara as Antibacterial Agent on Biofilm and Planktonic Cell of Aggregatibacter Actinomycetemcomitans
}

\author{
Suhad M. Hamdon, Ghada Y. Abdul-Rahman* \\ Department of Dental Basic Science, College of Dentistry, University of Mosul \\ *Corresponding author: aghadakahwaji@gmail.com
}

Received March 24, 2014; Revised April 17, 2014; Accepted April 17, 2014

\begin{abstract}
Aims: The aim of the study was to evaluate the susceptibility of Aggreagatibacter actinomycetemcomitans to licorice root (Glycyrrhiza glabara) extracts and to compare the antibacterial effect of this extract on biofilm versus planktonic cell. Materials and Methods: Subgingival plaque samples were taken to obtain fresh clinical isolates of A. actinomycetemcomitans. The isolates were divided into: biofilm positive (biofilm cell) and biofilm negative (planktonic cell) using crystal violet assay. Well diffusion method has been used to assess and compare the antibacterial effect of the ethanolic and aqueous extract of Glycyrrhiza glabara (licorice root) on the biofilm and planktonic clinical isolates of A. actinomycetemcomitans. Licorice root extracts were prepared at different concentrations: $(50 \mu \mathrm{g}),(100 \mu \mathrm{g}),(250 \mu \mathrm{g})$, tetracycline at concentration $(25 \mu \mathrm{g})$ used as control positive, and DMSO (dimethyle sulphaxsazol) for alcoholic licorice extract and sterile water as control negative for aqueous licorice extract. Results: Antimicrobial sensitivity test proved that (licorice root extract has good antibacterial effect against A actinomycetemcomitans and this effect was less against biofilm cell when compared with planktonic cell, and the effective concentration of licorice extracts was $250 \mu \mathrm{g}$ which produced inhibition zone compatible to tetracycline. Conclusions: This study proved that licorice extract had antibacterial effect against A. actinomycetyemcomitans, and this effect was decreased on biofilm phenotype which is more resistant to antimicrobial agents.
\end{abstract}

Keywords: Aggregatibacter actinomycetemcomitans, Glycyrrhiza glabara, biofilm, planktonic

Cite This Article: Suhad M. Hamdon, and Ghada Y. Abdul-Rahman, "Glycyrrhiza Glabara as Antibacterial Agent on Biofilm and Planktonic Cell of Aggregatibacter Actinomycetemcomitans." International Journal of Dental Sciences and Research, vol. 2, no. 2 (2014): 42-46. doi: 10.12691/ijdsr-2-2-4.

\section{Introduction}

A.actinomycetemcomitans is a Gram-negative facultative non-motile cocobacilli, oral commensal, often found in association with localized aggressive periodontitis, a severe infection of the periodontium, although it is also associated with non-oral infections [1]. The species has attracted attention because of its several virulence factors: Leukotoxin, kills PMNs and monocytes, cytolethal distending toxin Inhibits PMNs functions, surface adhesion Lipopolysaccharides have important role in biofilm formation, antimicrobial resistance [2], with respect to biofilm formation, its known that fresh clinical isolates of A.actinomycetemcomitans is usually form translucent rough colonies on agar medium and grow as a tight biofilm at the bottom of culture vessels in broth culture $[3,4]$. Sub culturing the isolates lead to the occurrence of opaque smooth colonial variants that lack biofilm formation ability [5]. Glycyrrhiza glabra, also known as licorice and sweet wood, it is used as a flavoring agent to mask the bitter taste in medical preparations. Licorice has many pharmaceutical properties such as anti- ulcer, anti-inflammatory, anti-carcinogenic, anti-viral, and anti-bacterial effects. Licorice extracts have been used to treat chronic hepatitis, and also have therapeutic benefit against other viruses, including human immunodeficiency virus (HIV), cytomegalovirus (CMV), and Herpes simplex. Deglycyrrhizinated licorice (DGL) preparations are useful in treating various types of ulcers, while topical licorice preparations have been used to smoothen and heal skin eruptions, such as psoriasis and herpetic lesions $[6,7]$.

\section{Materials and Methods}

\subsection{Samples Collection \& Transport}

Supra-gingival plaque was removed using a sterile curette, the supra-gingival area was dried with sterile gauze. Sub-gingival plaque samples were collected by inserting sterile paper point size 50 into the deep pockets of patients, who attended the Dental hospital, Department of Periodontics, College of Dentistry at Mosul University asking for diagnosis and treatment and placed in sterile vials containing $5 \mathrm{ml}$ brain heart infusion broth. 


\subsection{Bacterial Cultivation}

Dentaid-1 was prepared using brain heart infusion agar to which the following compounds were added: $5 \mathrm{~g}$ yeast extract, $1.5 \mathrm{~g}$ sodium fumarate, $1 \mathrm{~g}$ sodium formate per liter. The medium was autoclaved for $15 \mathrm{~min}$ at $121^{\circ} \mathrm{C}$. The final $\mathrm{pH}$ was $7.2 \pm 0.2$. Once the medium was cooled to $50^{\circ} \mathrm{C}$, vancomycin was added to a final concentration of $9 \mu \mathrm{g} / \mathrm{ml}$ [8]. incubation at $37 \mathrm{C}^{\circ}$ for $48-72$ hrs under anaerobic condition using anaerobic candle jar. Identification of A.actinomycetemcomitans based on colony morphology, gram stain (gram negative coccobacilli) and catalase test (rapid catalase positive) $[9,10]$ and molecular (PCR) identification kit (Genekam Com.) [11].

\subsection{Biofilm Formation Assessment}

A quantitative assessment of biofilm formation was determined as previously described by Christensen et al [12]. Biofilm formation on glass surface was estimated by conventional crystal violet staining method $A$. actinomycetemcomitans strains were cultivated overnight in TSBY (3\% tryptic soy broth (Difco Comp.) Supplemented with $0.5 \%$ yeast extract, $0.8 \%$ glucose , $0.4 \%$ sodium bicarbonate $(20 \mathrm{~mL})$. The tubes were decanted and washed with phosphate buffer saline $(\mathrm{pH}$ 7.3). The cells adsorbed on the culture vessel were scraped off with sterile spatula and the aggregates briefly dispersed by vortex then a culture containing approximately $6 \times 10^{8}$ colony-forming units(tube 2 MacCferland was inoculated in sterile $20 \mathrm{ml}$ of TSBY broth tubes containing 6 glass slides measured $1 \mathrm{~cm}^{2}$, the tubes were cultivated anaerobically for $48 \mathrm{hrs}$ at $37^{\circ} \mathrm{C}$, the glass slides were gently washed in (PBS, ph 7.2) and the cells adsorbed on the glass slide were stained with $1 \mathrm{ml}$ of $(0.1 \%)$ crystal violet solution for 10 minute., Excess stain was washed with PBS, the dye absorbed by the biofilm eluted in $1 \mathrm{ml}$ of $95 \%$ ethanol for each glass slid, the dyeeluted solution were 20 fold diluted with 95\% ethanol, then the absorbance was measured at $570 \mathrm{~nm}$ with spectrophotometer [13]. The clinical isolates were classified into positive and negative (planktonic) biofilm former according to the absorbance(high absorbance mean strong biofilm formation while very little absorbance mean weak or non-biofilm formation. Experiments were performed in triplicate for each isolates of A.actinomycetemcomitan [12]. To compare susceptibility of biofilm cell with planktonic cell. The clinical isolates that classified as negative biofilm former by crystal violet staining method which produce turbid growth, cannot adhere to the vessels wall and had no star like inner structure and sub-cultured several time were used as planktonic cell isolates [14].

\subsection{Preparation of Glycyrrhiza Glabra Extract}

Ethanolic extract prepared by grinding $250 \mathrm{~g}$ of Glycyrrhiza glabara, socked in 95\% ethanol for 72 hrs in sealed container at room temperature then filtered by many layers of sterile gauze to get rid of gross ruminates, alcohol was removed by rotary evaporator, the extract were dissolved in organic solvent (DMSO), and placed inside tightly capped vials in the refrigerator, aqueous extract prepared by grinding 250 g of Glycyrrhiza glabara, socked in sterile distilled water for 72 hrs in sealed container at room temperature then filtered by many layers of sterile gauze to get rid of gross ruminates, water was removed by rotary evaporator [15].

\subsection{Antimicrobial Sensitivity Test}

The antimicrobial effect of Glycyrrhiza glabara was estimated by well-Diffusion method, it was performed as prescribed by National Committee for Clinical Laboratory Standards (NCCLS). Muller Hinton agar was prepared, wells were punched with cupper ring $(5 \mathrm{~mm})$ sterilized by alcohol flaming and the plates were inoculated with standard inoculums(0.5 macCferland) equal to $1.5 \times 10^{8}$ CFU, and different concentration of $50 \mu \mathrm{l}$ Glycyrrhiza glabara extract : $1 \mathrm{~g} / \mathrm{ml}, 2 \mathrm{mg} / \mathrm{ml}, 5 \mathrm{mg} / \mathrm{ml}$, and of 0.5 $\mathrm{mg} / \mathrm{ml}$ tetracycline used as control +ve, the organic solvent or water as control -ve, placed in the wells by micropipette, so the concentration of the extract in each well will be $50 \mu \mathrm{g}, 100 \mu \mathrm{g}, 250 \mu \mathrm{g}$ for each concentration respectively and $25 \mu \mathrm{g}$ tetracycline. The antimicrobial sensitivity test was performed for each of the 5 biofilm isolate and 5 planktonic isolates of A.actinomycetemcomitans using aqueous and ethanolic extract of Glycyrrhiza glabra, the test done in triplicate for each isolate, the mean of zones of inhibition for each concentration of extract and for tetracycline were measured and compared [16].

\section{Results}

The results showed that adherent (biofilm) cell of fresh clinical isolates of A.actinomycetemcomitans produced colonies that had star shape inner structure when examined under low power light microscope (X10) compared with planktonic non adherent (non-biofilm) isolates which also obtained by several sub-culturing. Figure 1 (A) and (B). Biofilm formation assay using crystal violet method showed that when fresh isolates inoculated in $20 \mathrm{ml}$ TSYB tubes and incubated for $24 \mathrm{hrs}$ the cells were adhere to the glass slides leaving the broth clear, according to the absorbance the isolates were classified as biofilm positive(absorbance more than 0.1) while none adherent isolates produce turbid broth classified as negative biofilm (absorbance less than 0.1) The results of antibacterial sensitivity test showed that Glycyrrhiza glabara has antibacterial effect against A.actinomycetemcomitans. Table 1 showed the mean inhibition zone $(\mathrm{mm})$ for 5 planktonic isolates of $A$. actinomycetemcomitans produced by ethanolic Glycyrrhiza glabra extract: (11 mm, $19.2 \mathrm{~mm}, 22.4 \mathrm{~mm}$ ) diameter for: (50 $\mu \mathrm{g}-100 \mu \mathrm{g}-250 \mu \mathrm{g})$ concentration of ethanolic extract respectively these measurements were greater than the mean inhibition zone of aqueous extract at the same concentrations shown in Table 2 (10 mm, 12.6 $\mathrm{mm}, 13.6 \mathrm{~mm}$ ) diameter for: (50 $\mu \mathrm{g}-100 \mu \mathrm{g}-250 \mu \mathrm{g})$ concentration of aqueous extract respectively against the same planktonic isolates of $A$. actinomycetemcomitans, the ethanolic extract at $250 \mu \mathrm{g}$ concentration produced mean of inhibition zone $(22.4 \mathrm{~mm})$ diameter in Table 1 compatible to the mean of inhibition zone produced by tetracycline at $(25 \mu \mathrm{g})$ concentration which was $(22.2 \mathrm{~mm}$ -23.2 mm) diameter In Table 1, Table 2 respectively. 
Figure $2 \mathrm{~A}$ and $\mathrm{B}$ ) showed the larger inhibition zone of ethanolic extract than aqueous extract. The result in Table 3 and Table 4 showed that biofilm isolates which were determined by crystal violet assay more resistant than planktonic isolates, Table 3 showed the inhibition zone (mm) of ethanolic extract on biofilm cells in which the means of inhibition zones for 5 isolates were 6.8, 7.6, 10.8 $\mathrm{mm}$ at(50 $\mu \mathrm{g}-\mu \mathrm{g}$ 100-250 $\mu \mathrm{g})$ of extract respectively, even for $25 \mu \mathrm{g}$ tetracycline the mean of inhibition zone was (10.6 mm). Table 4 show means of inhibition zones of aqueous licorice root extract which at the same concentrations of ethanolic extract (50 $\mu \mathrm{g}-\mu \mathrm{g}$ 100-250 $\mu \mathrm{g}$ ) produced means of inhibition zones (6.2, 7, 7.2) respectively, Figure 3 and Figure 4 showed the inhibition zone of ethanolic and aqueous extract on biofilm and planktonic cells respectively.

\section{Discussions}

The recurrent, persistent infection in patients with aggressive periodontitis, antibiotic resistance, ability for biofilm formation of A.actinomycetemcomitans Candidate the search for using new antimicrobial agents. The development of resistance against antibiotics and antiseptics is a growing cause of concern which have limited the preventive measures. Therefore, there is a continuing need to search for new antimicrobial agents [17]. The ethanolic extract of G. glabra had effective MIC values against all oral bacteria especially $S$. mutans, A. viscosus, and E. faecalis and exhibited the highest MIC value against E. coli, so maybe antibacterial activity of G. glabra against gram positive bacteria was more than gram negative bacteria [18]. In this study the ethanolic licorice root extract has better effect than aqueous extract against the oral pathogen A.actinomycetemcomitans. The killing efficacy of achievable peak serum concentration of cefazolin, vancomycin, dicloxacillin, tetracycline and rifampicin was less than 10-fold higher against S.epidermidis cell in biofilm. This decrease in the efficacy is still quite significant [19]. Our study also revealed that biofilm cells of A.actinomycetemcomitans were more resistance to licorice root extracts $S$. aureus is a major clinical pathogen. During the past decade, this bacterium has developed resistance to many commonly used antibiotics. In study, the extracts of Glycyrrhiza glabra showed activity against $S$. aureus and can be used as raw materials for phytotherapy [20].

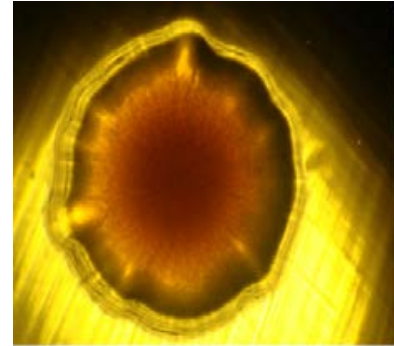

(A)

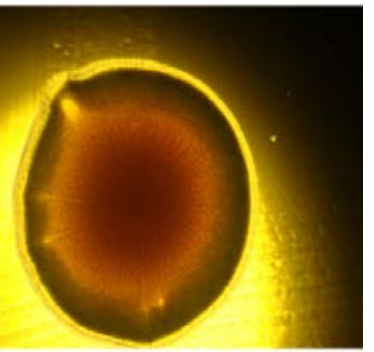

(B)
Figure 1. Representative light microscope image (10X) of colony morghology of A.actinomycetemcomitans clinical isolates A biofilm colony, B planktonic colony

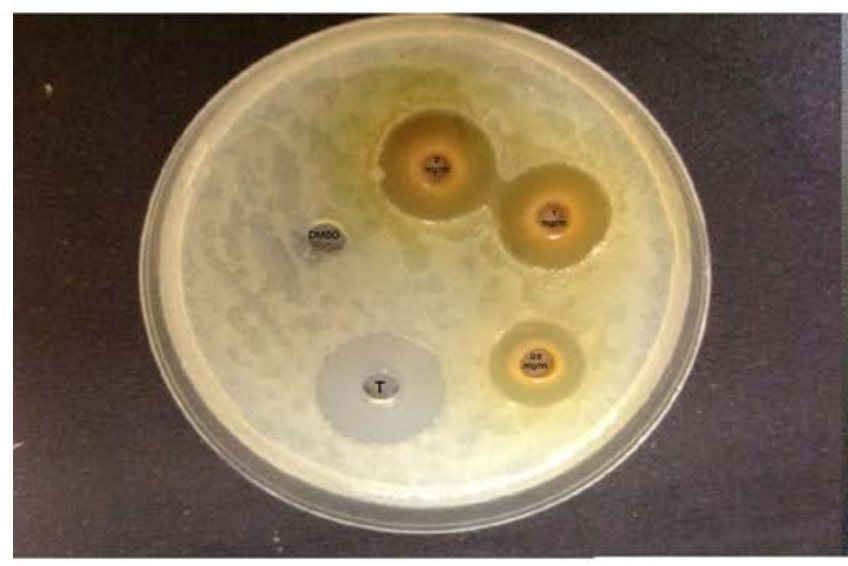

(A)

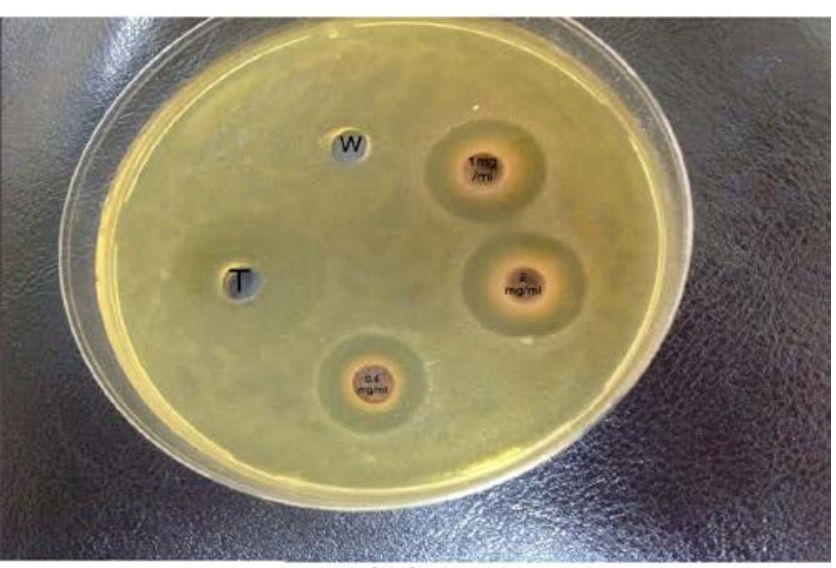

(B)

Figure 2. well diffusion method of antibacterial effect of (A)Ethanolic and(B) Aqueous extract of Glycyrrhiza glabara on planktonic cell of $A$. actinomycetemcomitan

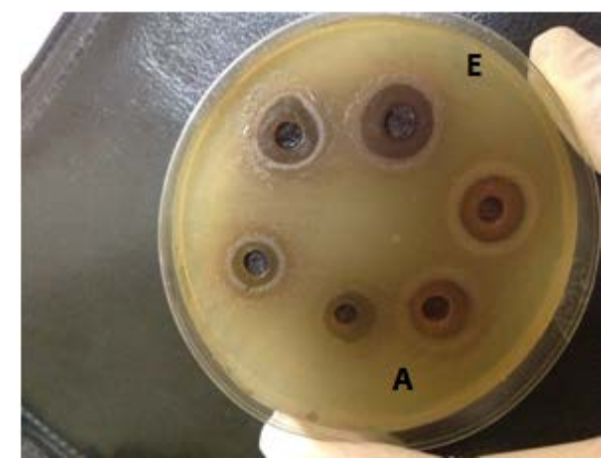

Figure 3. well diffusion method of antibacterial effect of Ethanolic and Aqueous extract of Glycyrrhiza glabara on planktonic cell of A.actinomycetem

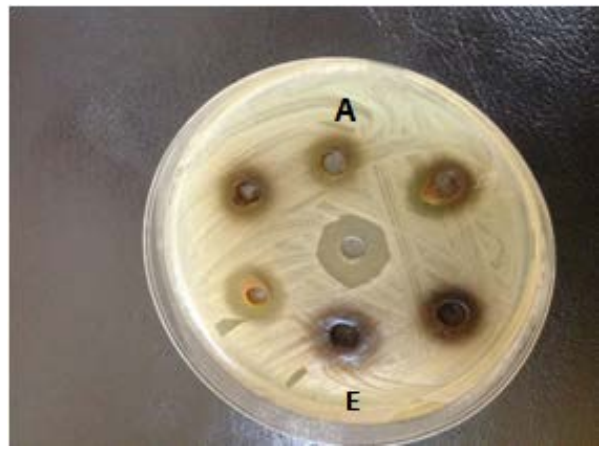

Figure 4. well diffusion method of antibacterial effect of Ethanolic and Aqueous extract of Glycyrrhiza glabara on biofilm cell of A.actinomycetemcomitans 
Table 1. Inhibition zone measurement $(\mathrm{mm})$ of Table 1 inhibition zone measurement(mm) of ethanolic Glycyrrhiza glabra extract for planktonic cell of A. actinomycetemcomitans

\begin{tabular}{|c|c|c|c|c|c|c|c|}
\hline \multirow{2}{*}{ Extract } & \multirow{2}{*}{ Conc. $(\mu \mathrm{g})$} & \multicolumn{5}{|c|}{ Zone of inhibition (in mm diameter) } & \multirow{2}{*}{ Mean } \\
\cline { 3 - 8 } & & $*$ No. 1 & $*$ No. 2 & $*$ No. 3 & $*$ No. 4 & *No. 5 & 12 \\
\hline Glycyrrhiza glabara & $50 \mu \mathrm{g}$ & 12 & 11 & 10 & 12 & 10 & 11 \\
\hline Glycyrrhiza glabara & $100 \mu \mathrm{g}$ & 17 & 20 & 20 & 19 & 20 & 19.2 \\
\hline Glycyrrhiza glabara & $250 \mu \mathrm{g}$ & 20 & 22 & 25 & 22 & 23 & 22.4 \\
\hline Tetracycline & $25 \mu \mathrm{g}$ & 20 & 23 & 22 & 20 & 26 & 22.2 \\
\hline DMSO** & & 0 & 0 & 0 & 0 & 0 & 0 \\
\hline
\end{tabular}

*Inhibition zone measured in mm.

** Dimethyl sulphaxazol

Table 2. Inhibition zone measurement $(\mathrm{mm})$ of aqueous Glycyrrhiza glabra extract for planktonic cell of $A$. actinomycetemcomitans

\begin{tabular}{|c|c|c|c|c|c|c|c|}
\hline \multirow{2}{*}{ Extract } & \multirow{2}{*}{ Conc. $(\mu \mathrm{g})$} & \multicolumn{5}{|c|}{ Zone of inhibition (in mm diameter) } & \multirow{2}{*}{ Mean } \\
\cline { 3 - 7 } & & $*$ No. 1 & $*$ No. 2 & $*^{*}$ No. 3 & ${ }^{*}$ No. 4 & No. 5 & \\
\hline Glycyrrhiza glabara & $50 \mu \mathrm{g}$ & 9 & 10 & 10 & 10 & 11 & 10 \\
\hline Glycyrrhiza glabara & $100 \mu \mathrm{g}$ & 12 & 13 & 12 & 13 & 13 & 12.6 \\
\hline Glycyrrhiza glabara & $250 \mu \mathrm{g}$ & 14 & 14 & 13 & 14 & 13 & 13.6 \\
\hline Tetracycline & $25 \mu \mathrm{g}$ & 22 & 22 & 25 & 22 & 25 & 23.2 \\
\hline Water & & 0 & 0 & 0 & 0 & 0 & 0 \\
\hline
\end{tabular}

Table 3. inhibition zone measurement (mm) of ethanolic Glycyrrhiza glabra extract for biofilm cell of A. actinomycetemcomitans

\begin{tabular}{|c|c|c|c|c|c|c|c|}
\hline \multirow{2}{*}{ Extract } & \multirow{2}{*}{ Conc. $(\mu \mathrm{g})$} & \multicolumn{3}{|c|}{ Zone of inhibition (in mm diameter) } \\
\cline { 3 - 8 } & & $*$ No. 1b & No. 2b & No. 3b & No. 4b & No. 5b & Mean \\
\hline Glycyrrhiza glabara & $50 \mu \mathrm{g}$ & 7 & 6 & 7 & 7 & 7 & 6.8 \\
\hline Glycyrrhiza glabara & $100 \mu \mathrm{g}$ & 8 & 7 & 7 & 8 & 7 & 7.6 \\
\hline Glycyrrhiza glabara & $250 \mu \mathrm{g}$ & 11 & 11 & 10 & 12 & 10 & 10.8 \\
\hline Tetracycline & $25 \mu \mathrm{g}$ & 11 & 11 & 11 & 10 & 10 & 10.6 \\
\hline DMSO** & & 0 & 0 & 0 & 0 & 0 & 0 \\
\hline
\end{tabular}

Table 4. inhibition zone measurement (mm) of aqueous Glycyrrhiza glabra extract for biofilm cell of A. actinomycetemcomitans

\begin{tabular}{|c|c|c|c|c|c|c|c|}
\hline \multirow{2}{*}{ Extract } & \multirow{2}{*}{ Conc. $(\mu \mathrm{g})$} & \multicolumn{9}{|c|}{ Zone of inhibition (in mm diameter) } \\
\cline { 3 - 8 } & & $*$ No. 1b & No. 2b & No. 3b & No. 4b & No. 5b & Mean \\
\hline Glycyrrhiza glabara & $50 \mu \mathrm{g}$ & 7 & 6 & 7 & 6 & 5 & 6.2 \\
\hline Glycyrrhiza glabara & $100 \mu \mathrm{g}$ & 7 & 7 & 7 & 7 & 7 & 7 \\
\hline Glycyrrhiza glabara & $250 \mu \mathrm{g}$ & 7 & 7 & 8 & 7 & 7 \\
\hline Tetracycline & $25 \mu \mathrm{g}$ & 11 & 10 & 11 & 10 & 11 & 10.6 \\
\hline water & & 0 & 0 & 0 & 0 & 0 & \\
\hline
\end{tabular}

\section{Conclusions}

Glycyrrhiza glabra (licorice root) ethanolic extract have good antibacterial effect against A.actinomycetemcomitans at $250 \mu \mathrm{g}$ concentration and this effect reduced against biofilm isolates, therefore this extract or their active ingredients can be mixed with mouth washes or teeth paste, particularly their local administration can overcome many side effect systemic administration of this extract.

\section{References}

[1] Zambon, J. (1985) Actinobacillus actinomycetemcomitans in human periodontal disease. J. Clin Periodontol. Vol. 12, P: 1-20.

[2] Slots J (1976). "The predominant cultivable organisms in juvenile periodontitis". Scand J Dent Res, January 84 (1): 1-10.

[3] Inoue, T., Ohata, H., Tanimoto, I., Shingaki, R., and Fukui, K. (2000) Heterogenous post-translational modification of Actinobacillus actinomycetemcomitans fimbirillin. Microbiol. Immunol. 44 P: 715-712.

[4] Inoue, T., Tanimoto, I., Tada, T., Oshashi, T., Fukui, K. and Ohata, H. (2001) Fermentable-sugar-level-dependent regulation of leukotoxin synthesis in variably toxic strain of Actinobacillus actinomycetemcomitans. Microbiology 147 P.: 2749-2756.

[5] Ishihara K, Honma K,Miura T et al. (1997) Cloning and sequence analysis of the fimbria assotiated protien (fap) gene from Actinobacillus actinomycetemcomitans Microb Pathog; 23: 63-9.

[6] Glycyrrhiza glabra (2005) Alternative Medicine Review Vol. 10, No. 3 September, p. 230-237.
[7] Shibata, S (2000) "A drug over the millennia: pharmacognosy, chemistry, and pharmacology of licorice." Yakugaku Zasshi, Oct 120 (10): 849-62.

[8] Alsina M., Olle E., Frias J. (2001). Improved. Low-Cost Slective Culture Medium of Actinobacillus actinomycetemcomitans J.Clin Microbiol 39: 509-513.

[9] Alcoforado, G. A. P., T. L. McKay, and J. Slots. (1987) Rapid method for detection of lactose fermenting oral microorganisms. Oral Microbiol. Immunol. 2: 35-38.

[10] Norskov-Lauritsen $\mathrm{N}$ and Kilian $\mathrm{M}$. Reclassification of Actinobacillus actinomycetemcomitans, Haemophilus aphrophilus, Haemophilus paraphrophilus and Haemophilus segnis as Aggregatibacter actinomyctemcomitans gen. nov., comb. nov., Aggregatibacter aphrophilus comb. nov. and Aggregatibacter segnis comb. nov., and emended description of Aggregatibacter aphrophilus to include $\mathrm{V}$ factor-dependent and $\mathrm{V}$ factorindependent isolates. (2006) Int J Syst Bacteriol; 56: 2135-2146.

[11] Preus HR Sunday GJ Haraszthy VI et al. (1992) Rapid identification of Actinobacillus actinomycetemcomitans, based on analysis of 23S rRNA, Oral Microbiol Immunol; 7: 372-375.

[12] Christensen GD, Simpson WA, Younger JA, Baddour LM, Barrett FF, Melton DM, et al. (1985) Adherence of cogulase negative Staphylococi to plastic tissue cultures:a quantitative model for the adherence of staphylococci to medical devices. J Clin Microbiol; 22: 996-1006

[13] O, Toole,G.A.,and Kolter,R (1998) Initiation of biofilm frmation in Pseudomonasfluorescence WCS365 proceed via multiple convergent signaling pathways:agenetic analysis Mol. Microbiol. 28: 449-461.

[14] Fine DH, Furgang D, Schreiner HC.et al. (1999) Phenotypic variation in Actinobacillus actinomycetemcomitans during laboratory growth: implications for virulence. Microbiology; 145: 1335-1347.

[15] More G, Tshikalange TE, Lall N, Botha F, Meyer JJM. (2008). Antimicrobial activity of medicinal plants against oral microorganisms Journal of Ethnopharmacology, 119: 473-477. 
[16] National Committee for Clinical Laboratory Standards. 5. NCCLS Wayne PA; 2000.

[17] Cai L, Wu CD. (1996). Compounds from Syzygium aromaticum possessing growth inhibitory activity against oral pathogens. $J$ Nat Prod, 59: 987-90.

[18] Sedighinia F, Safipour Afshar A, Soleimanpour S, Zarif R, Asili J, Ghazvini J. (2012); Antibacterial activity of Glycyrrhiza glabra against oral pathogens: an in vitro study Avicenna J Phyto Med. 3: 118-124.
[19] -Cerca, N., Martins, S., Cerca, F., Jefferson, K., Gerald, P., Oliveira, R., Azeredo, J. (2005) Comparative assessment of antibiotic susceptibility of coagulase-negative Staphylococci in biofilm versus planktonic culture as assessed by bacterial enumeration or rapid XTT colorimetry Antimicrobial Chemotherapy 56, :331-336,

[20] Marananan MM, Moreiar B, Boyle-Vavra S and Daum RS. (1997) Antimicrobial resistance in Staphylococci. Infect. Dis. Clinic North Am. 11: 813-8. 